\title{
ANÁLISE DA COMUNIDADE MICROBIOLÓGICA E A GERAÇÃO DE ENERGIA POR CÉLULAS DE ENERGIA MICROBIOLÓGICAS COM DIFERENTES TIPOS DE ÂNODOS
}

\author{
G. R. LAMAS-SAMANAMUD ${ }^{1}$, M. HOFFER ${ }^{2}$, T. JIANG ${ }^{3}$ e C. C. A. LOURES ${ }^{4}$ \\ University of Texas at San Antonio ${ }^{1,2,3}$, Centro Federal de Educação Tecnológica Celso Suckow da Fonseca \\ zgisella@gmail.com ${ }^{1}$
}

Submetido 09/02/2017 - Aceito 28/03/2020

DOI: $10.15628 /$ holos.2020.5645

\section{RESUMO}

As Células de Energia Microbiológicas (CEMs) são uma tecnologia promissora na geração de bioeletricidade a partir de biomassa usando bactérias, ou seja, convertendo resíduos em produtos energéticos. Este estudo usou uma câmara de CEM simples e amostras de efluente de uma estação de tratamento de efluentes municipal para convertê-las em energia. De forma a verificar a eficiência da CEM, cinco câmaras simples foram utilizadas, cada uma com sua própria conformidade de material anódico. As câmaras consistiram em quatro Discos de Carbono (DC) com composições variáveis de carbono e uma Escova de Fibra de Carbono (EFC). As densidades de potência máxima de EFC, DC1 e DC2 mostraram uma tendência decrescente, sendo esta $24 \mathrm{~mW} / \mathrm{m}^{3}, 20 \mathrm{~mW} / \mathrm{m}^{3}, \quad 8 \mathrm{~mW} / \mathrm{m}^{3}$, respectivamente. A análise da comunidade microbiológica foi realizada para comparar a composição microbiológica encontrada em cada câmara e identificar uma possível relação na geração de bioeletricidade. Os resultados, através da Clonagem Shotgun e DGGE, mostraram que os microrganismos na câmara EFC foram os que variaram mais. Uma vez que ambos os grupos Geobacter e Chlorobium foram identificados como os mais predominantes, uma análise por q-PCR foi conduzida. A porcentagem entre os grupos foi de 80, 92 e $95 \%$ para Chlorobium e 55, 25 e $10 \%$ para Geobacter nas câmaras EFC, DC1 e DC2, respectivamente. A relação simbiótica de Chlorobium e Geobacter pode ser a chave para se aumentar a quantidade de eletricidade produzida biologicamente com este tipo de efluente.

PALAVRAS-CHAVE: células de energia microbiológica, análise de comunidade bacteriológica, bioenergia, tratamento de efluentes.

\section{MICROBIAL COMMUNITY ANALYSIS AND ELECTRICITY GENERATION OF MICROBIAL FUEL CELLS WITH DIFFERENT ANODIC MATERIALS}

\begin{abstract}
Microbial Fuel cells (MFC) represent a promising approach for bioelectricity generation from biomass using bacteria as they convert waste to energy products. This study used a single chamber MFC and wastewater samples from a municipal wastewater treatment facility to convert energy. To verify the efficiency of MFC, five single chambers were used each with its corresponding anodic material. Chambers consisted of five carbon disks (CD) with different composition of carbon and a carbon fiber brush (CFB). The maximum power densities of CFB, $\mathrm{CD} 1$ and $\mathrm{CD} 2$ showed a decreasing trend, being $24 \mathrm{~mW} /$ $\mathrm{m}^{3}, 20 \mathrm{~mW} / \mathrm{m}^{3}, 8 \mathrm{~mW} / \mathrm{m}^{3}$, respectively. Microbial community analysis was carried out to verify the
\end{abstract}

microbial composition of each chamber and thus, correlate the types of bacteria found with higher bioelectricity generation. Results from Shotgun cloning and DGGE showed that microorganisms in the CFB chamber varied the most. Since both Geobacter and Chlorobium species were found to be most predominant in both analyses a Q-PCR was carried out for both genes. Results showed that the gene ratio was 80,92 and $95 \%$ for Chlorobium and 55, 25 and 10\% for Geobacter to chambers $\mathrm{CFB}, \mathrm{CD} 1$ and $\mathrm{CD} 2$, respectively. A higher ratio in the symbiotic relationship of Chlorobium and Geobacter may be the key for higher bioelectricity generation for this type of wastewater sample.

KEYWORDS: microbial fuel cells, microbial community analysis, bioenergy, wastewater treatment. 


\section{INTRODUÇÃO}

A bactéria pode oxidar um substrato e, através da transferência de elétrons na membrana celular, é possível produzir eletricidade (Bond \& Lovley, 2003; Das \& Mangwani, 2010; Katuri \& Scott, 2010; Liu et al., 2004; Lovley, 2006; Potter, 1911; Rabaey et al., 2004). O sistema em que essa produção de corrente acontece é chamado de Células de Energia Microbiológicas (CEMs). De acordo com alguns autores (Fricke et al., 2008; Hu, 2008; Lovley, 2009; Sun et al., 2009; Torres, 2012), a taxa lenta de conversão dessas CEMs em combustível faz com que seu uso apresente um desafio ao se aumentar a escala operacional do processo.

No entanto, pesquisas nas últimas décadas (Baron et al., 2009; Cho et al., 2008; Greenman et al., 2009; Lee et al., 2010; Lloyd et al., 2003; Murali et al., 2013; Pant et al., 2010; Sun et al., 2011), mostraram uma perspectiva promissora para o uso de CEMs na comercialização, principalmente devido as outras possíveis aplicações para as CEMs além de fontes de energia. Um exemplo da aplicação dessa mesma habilidade de produção de corrente pode ser adaptado para o tratamento de contaminantes recalcitrantes, por exemplo (Greenman et al., 2009; Huang \& Logan, 2008; Jia et al., 2008; Kim et al., 1999; Li \& Jia, 2008; Liu et al., 2004; Murali et al., 2013; Rezaei et al., 2008; Shizas \& Bagley, 2004; Zuo et al., 2006). O princípio das CEMs consiste na transferência do próton do anodo ao catodo. Um sistema redox conduzido pelos microrganismos é formado no qual, de forma geral, o substrato doa elétrons para o $\mathrm{O}_{2}$ (1) e (2).

Reação anódica: Substrato $+\mathrm{H}_{2} \mathrm{O} \rightarrow 2 \mathrm{CO}_{2}+2 \mathrm{H}^{+}+8 \mathrm{e}^{-}$

Reação catódica: $\mathrm{O}_{2}+4 \mathrm{e}^{-}+4 \mathrm{H}^{+} \rightarrow 2 \mathrm{H}_{2} \mathrm{O}$

Pesquisas relacionadas ao grupo das Geobacter e o uso da biológica molecular como alvo de estudo vêm crescendo nas últimas décadas (Lovley, 2009; Marsili et al., 2008; Qian \& Morse, 2011; Richter et al., 2009; Sharma \& Kundu, 2010), contudo, poucos pesquisadores se concentraram em outros grupos bacteriológicos relacionados às CEMs. A referência (Sun et al., 2011) descreveu a composição biológica das CEMs inoculadas por lodo ativado de estações de tratamento de efluentes. Suas principais descobertas foram as populações de Geobacter, Thiococcus e Acitenobacter. Portanto, estudos envolvendo diferentes tipos de anodos e comunidade biológica que é predominante em cada tipo de anodo devem ser realizados de maneira a aumentar e ampliar a aplicação prática das CEMs.

O propósito deste estudo foi identificar quais microrganismos tiveram maior importância no processo de geração de energia. Nesse contexto, a análise de comunidade microbiológica foi realizada e identificada nas câmaras de CEM usando dois tipos de material anódico (discos de carbono grafítico e escova), comparando os resultados dos métodos de biblioteca de genes para a seguir relacionar os mesmos com a produção de energia.: 


\section{METOLOGIA}

\subsection{Material anódico}

Cinco materiais de carbono, EFC (escova de fibra de carbono, $35 \mathrm{~mm}$ de diâmetro), DC1 (disco de carbono contendo $60 \%$ carbono e $40 \%$ argila), DC2 (disco de carbono consistindo de 505 carbono e 50\% argila), DC3 (30\% carbono, 35\% grafite e 35\% argila), DC4 (20\% carbono, $40 \%$ grafite e $40 \%$ argila) foram usados como anodos neste estudo. Os materiais foram imersos em acetona por $12 \mathrm{~h}$ e secos à $400^{\circ} \mathrm{C}$ por $1 \mathrm{~h}$ para evitar a deposição de qualquer metal na superfície dos materiais de carbono.

\subsection{Construção e operação da CEM}

Uma câmara simples de CEM foi projetada, consistindo em um recipiente de vidro com volume total de $150 \mathrm{~mL}$. Uma folha de carbono foi usada como catodo e disposta em contato com o ar de forma a agir como um selante da câmara de CEM. Cinco câmaras simples foram usadas, cada uma contendo um tipo de material anódico. Cada câmara foi inoculada com o mesmo consórcio microbiológico coletado do efluente municipal. O meio anódico foi preparado com uma solução de PBS de acordo com a referência (Logan, 2008) consistindo em $\mathrm{NH}_{4} \mathrm{Cl}$ 0,62g/L, $\mathrm{NaH}_{2} \mathrm{PO}_{4}$ $4,9 \mathrm{~g} / \mathrm{L}, \mathrm{Na}_{2} \mathrm{HPO}_{4}$ 9,2g/L e KCl 0,26g/L. A solução foi reposta a cada 3 dias com solução de PBS (PBS + vitaminas e minerais). Todos os reatores foram mantidos em temperatura ambiente (20C) com um resistor de $1000 \Omega$.

\subsection{Análise eletroquímica}

A voltagem do reator de CEM foi medida num intervalo de tempo de 3 min usando um sistema de aquisição de dados Keithley 2700 Multímetro (Excelink). A corrente e a densidade de potência foram calculadas através das equações (3) e (4) em que I é a corrente, E a voltagem medida, $\mathrm{R}$ a resistência externa, $\mathrm{P}$ a densidade de potência, e $\mathrm{V}$ o volume neto líquido do compartimento anódico (Logan \& Regan, 2006).

$$
\begin{aligned}
& I=E / R \\
& P=I E / V
\end{aligned}
$$

Para obter a curva de polarização, a resistência externa foi ajustada de 100 para $700 \Omega$. A eficiência Coulômbica (EC) foi expressa como a razão dos Coulombs realmente produzidos pelos máximos Coulombs possíveis na remoção do substrato (Logan \& Regan, 2006).

\subsection{Análise da comunidade microbiológica}

A duração do experimento foi de 60 dias, e amostras do material anódico empacotado no compartimento da CEM foram tiradas no começo do experimento, após o primeiro ciclo e no final do experimento. As amostras do final do experimento foram filtradas e o sobrenadante foi denominado líquido puro e o precipitado foi denominado anodo. O DNA foi extraído das respectivas amostras usando o kit de isolamento Ultra Clean Microbial DNA (MO BIO Laboratories). Na amplificação do 16S rRNA da bactéria, o primer senso 8F (5'-AGA GTT TGA TCC TGG CTC AG-3') 
e o primer antisenso 1492R (5'-GGW TAC CTT GTT ACG ACT T-3') foram usados. Os produtos PCR amplificados foram purificados com o Kit de Purificação de PCR QIAquick.

As amostras do final do experimento foram ligadas ao Vetor pCR 4- Topo. Após ligação, o produto foi transformado em células competentes $\mathrm{MH}-\alpha 1$, que foram verificadas usando placas de Luria Bertani (LB), contendo kanamicina. Colônias brancas foram selecionadas e transferidas para tubos de PCR. Outra amplificação foi realizada usando os primers M13F (5'-GTA AAA CGA CCA G3') e M13R (CAG GAA ACA GCT ATG AC-3'). Os resultados de PCR foram submetidos para sequenciamento usando M13F.

Amostras do começo, após o 10 ciclo e final do experimento, foram submetidas a outro processo de PCR ("nested PCR" após a 1a amplificação usando 8F e 1492R, os primers senso e antisenso, respectivamente), no qual, os primers utilizados foram: 341F (5' -CGC CCG CCG CGC GGG CGG GGC GGG GCG GGG GCA CGG GGG CCT ACG GIG GCI GCA-3') com “GCclamp" e 533R (5'-TIA CCG III CTI CTG GCA C-3'). Após a amplificação, amostras foram submetidas à análise de DGGE (Eletroforese em Gel de Gradiente de Desnaturação) usado DGGE Biorad D code e Biorad Powerpac Basic. O gel foi analisado em Biorad Gel Doc XR. As amostras foram cortadas e submetidas a uma nova série de PCR sem lonosina. Os primers usados foram 341F sem I (5' - CGC CCG CCG CGC GCG GCGNGGC GGG GGC ACG GGG GCC TAC GGG AGG CAG CAG-3') e 533R sem I (5'-ATT ACC GCG GCT GCT TGG-3').

As amostras foram então purificadas usando o Kit de Purificação de PCR QIAquick e enviadas para o sequenciamento com os primers $341 \mathrm{~F}$ sem o GC clamp (5'-CCT ACG GGA GGC AGC AG-3'). Os resultados do sequenciamento de ambos, clonagem Shotgun e as bandas de DGGE, foram analisadas com BLAST (Ferramenta Básica de Alinhamento Local de Sequências) via o Centro Nacional para Informação Biotecnológica (http://www.ncbi.nlm.nih.gov/BLAST/).

\section{RESULTADOS E DISCUSSÕES}

\subsection{O desempenho da CEM}

As Figuras 1a e 1b mostram mudanças na densidade de potência e o potencial do eletrodo (versus o eletrodo de hidrogênio padrão) com a densidade de corrente para CEMs empacotadas com diferentes materiais anódicos. EFC empacotada na CEM apresentou maior densidade de potência dentre as cinco CEMs.

As densidades de potência máxima para EFC, DC1 e DC2 mostraram uma tendência decrescente, sendo os valores encontrados de $24 \mathrm{~mW} / \mathrm{m} 3,20 \mathrm{~mW} / \mathrm{m} 3,8 \mathrm{~mW} / \mathrm{m} 3$, respectivamente. Os discos de carbono 3 e 4 que continham grafite não foram estáveis durante todo o experimento, desintegrando-se conforme o tempo, o que não permitiu a leitura da densidade da potência para esses tipos de materiais. A Figura $1 \mathrm{~b}$ indicou que a mudança do material do anodo interfere nas densidades de potência das CEMs.

Os materiais do anodo e os biofilmes ligados a eles foram os principais fatores influenciando as características dos anodos. Embora os três materiais anódicos tenham composições similares, o conteúdo de argila para o DC2 parece indicar que, quanto maior a porcentagem de argila no anodo, menor o potencial do eletrodo. Isto pode ser explicado pela baixa condutividade da argila. 


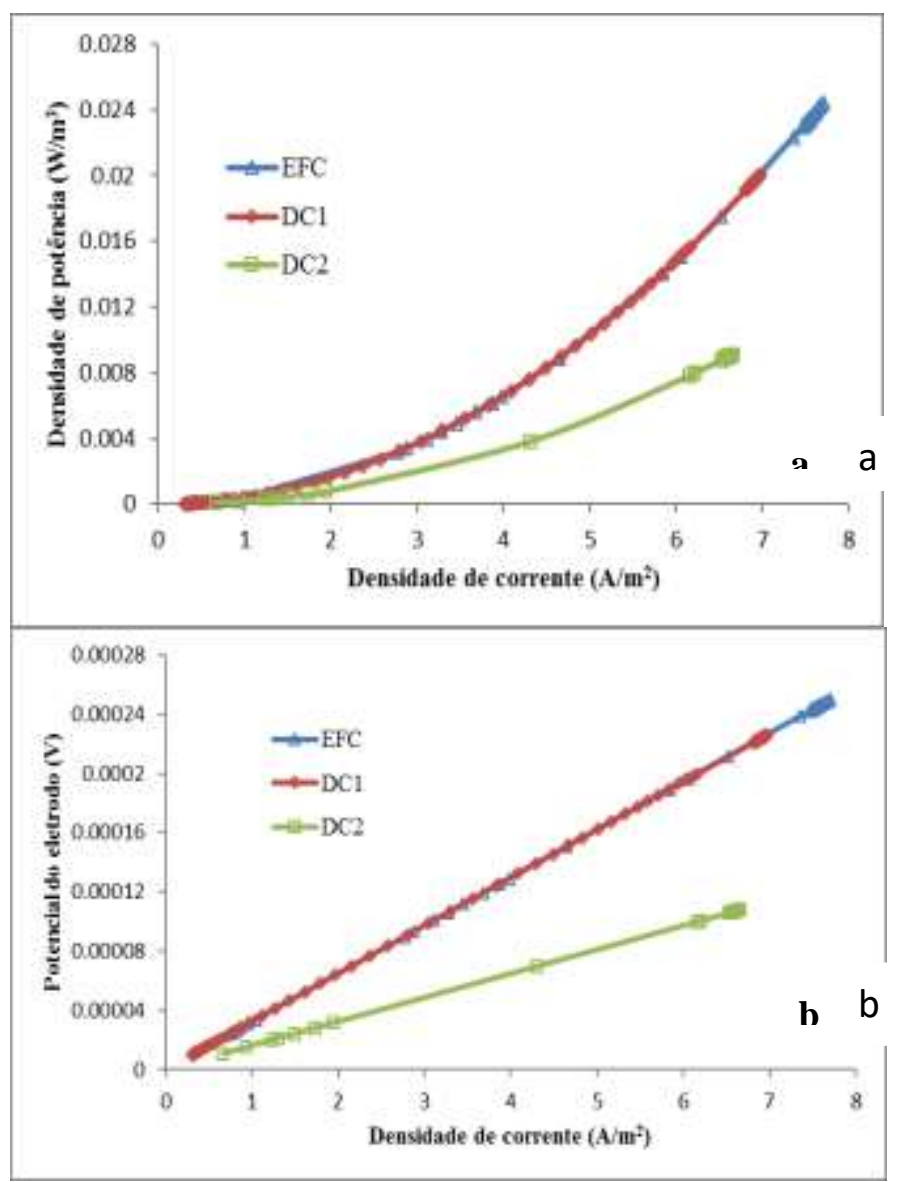

Figura 1: Densidade da potência - (a) e potenciais do eletrodo como função da densidade de corrente; (b) para as CEMs empacotadas com diferentes materiais anódicos (EFC, DC1, DC2).

A maior produção de energia e densidade de potência é vista para EFC que pode ser explicada pelo fato de que a superfície da escova favorece a deposição do biofilme no anodo. Portanto, as condições oferecidas pela EFC podem contribuir para a maior quantidade de energia gerada.

\subsection{Análise de diversidade com o método de biblioteca genômica}

Para encontrar a influência dos materiais anódicos na composição e estrutura da comunidade microbiológica, o biofilme ligado aos materiais anódicos empacotados nas CEMs foi analisado quanto ao 16SrRNA e ao método da biblioteca genômica no final do experimento (Tabela 1). 12 clones positivos (OTUs - Unidades Taxonômicas Operacionais) foram escolhidos aleatoriamente das bibliotecas microbiológicas de cada material anódico para sequenciamento como mostra a Tabela 1 e os tipos de microrganismos encontrados podem ser vistos na Figura 2.

Como pode ser visto na Figura 2, a diversidade microbiológica foi relativamente a mesma para todos os materiais anódicos. No DC2, porém, a capacidade de geração de energia foi a mais baixa quando comparada com as outras três embora a comunidade microbiológica seja parecida à encontrada para a EFC. Isto vai de encontro à literatura (Sun et al., 2011; Dias et al., 2019) que sugere que a mera diversidade biológica não é a que determina a quantidade de corrente, mas sim o tipo de microrganismo presente nessa diversidade pode estar associado à geração de energia. Portanto, conhecer e entender a comunidade microbiológica é crucial para poder relacionar uma 
geração de energia mais eficiente ao tipo específico de microrganismos encontrados no material anódico na forma de biofilme.

Os resultados mostraram que os microrganismos na EFC da CEM variaram mais, e a comunidade microbiológica consistiu em Geobacter, Myxococcus, Ignavibacterium, Chlorobium, Korkinobacter, Alistipes, Rhodopseudomonas, Xanthomonas, Citrumelo. O biofilme anódico do DC1 foi predominante de Rhodopseudomonas, Alistipes, Chlorobium, Geobacter, Aminobacterium. O DC2 consistiu em Chlorobium, Rhodopseudomonas, Erysipelothrix, Caldisericum, Oscillobacter. Dentro da diversidade microbiológica das três CEMs, Chlorobium e Rhodopseudomonas parecem estar presentes em todas as CEMs enquanto que Geobacter é recorrente em ambas EFC e DC1.

Tabela 1: Bibliotecas genômicas 16S rRNA bacteriológico de diferentes materiais anódicos empacotados nas CEMs.

\begin{tabular}{c|c|c|c}
\hline \multirow{2}{*}{ Tipo de Anodo } & \multicolumn{3}{|c}{ Clonagem } \\
\cline { 2 - 4 } & Número de transformados & Número de clones positivos & OTUs \\
\hline EFC & 51 & 49 & 12 \\
DC1 & 106 & 98 & 11 \\
DC2 & 68 & 59 & 12 \\
\hline
\end{tabular}

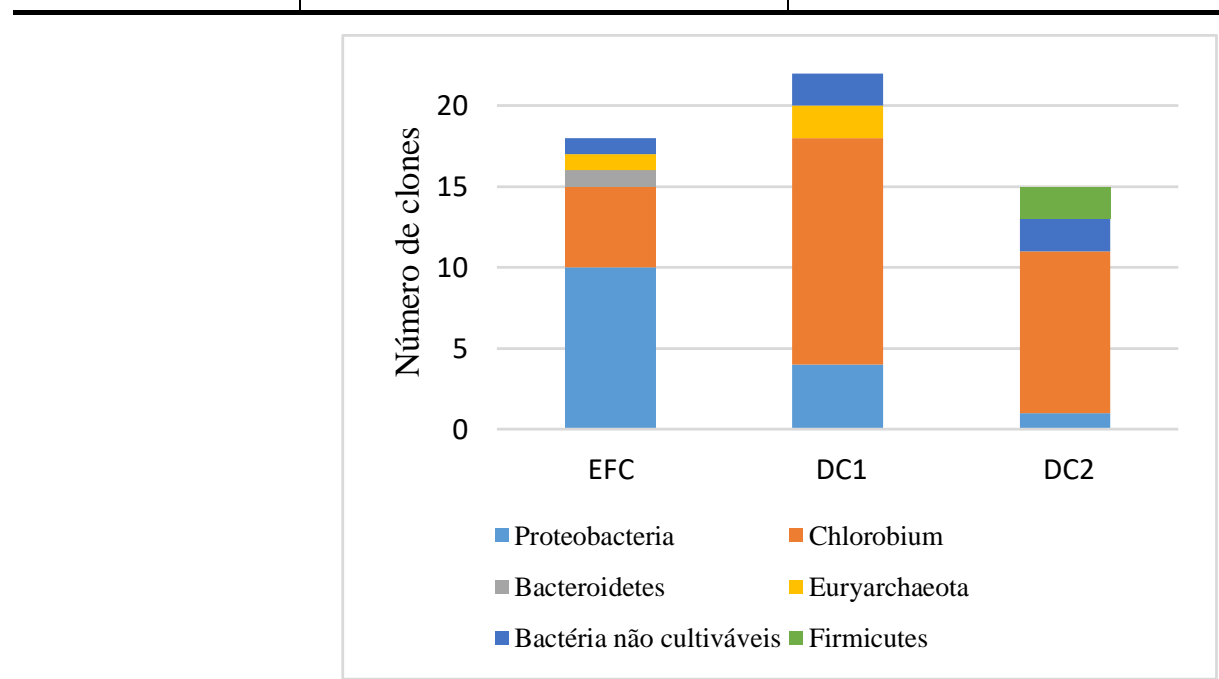

Figura 2: Análise da comunidade microbiológica para três materiais anódicos diferentes (EFC, DC1, DC2) após clonagem Shotgun.

De forma geral, embora as amostras de DC2 mostraram uma variedade de clones positivos para serem sequenciados, a análise da comunidade microbiológica revelou que o seu material anódico era constituído principalmente por Chlorobium. Já a EFC e o DC1, mostraram a presença de Geobacter, sendo este mais predominante na EFC e consistente com o estudo realizado (Logan, 2008) que sugere que o aumento na geração de energia se deve à presença de Geobacter no meio anódico.

\subsection{Diversidade microbiológica com o tempo (análise DGGE)}

A Figura 3 mostra que a comunidade microbiológica varia com o tempo e essas diferenças são notáveis desde o início de experimento, após o 1으 ciclo e no final do experimento. Como podese ver na Figura 3, DC3 e DC4 não são mostrados no gel DGGE ao final do experimento, porque o material anódico desintegrou-se desintegrou com o tempo inviabilizando as análises seguintes. 
A primeira amostra corresponde ao efluente pode ser vista na Figura 3, não há bandas mais brilhantes do que as outras. Isso indica uma grande variedade microbiológica sem que algum microrganismo seja predominante sobre os outros. Uma mudança clara pode ser vista nas faixas 2 e 3 quando o efluente já se encontra em contato com o material anódico e envolvido pela solução de PBS contendo vitaminas e minerais. Nessa etapa, já há uma seleção natural da comunidade microbiológica. A concentração de oxigênio é importante durante o 1 o ciclo do experimento da CEM. Bandas mais evidentes são mostradas em posições diferentes no gel quando comparadas àquelas do início do experimento. A seleção continua no final do experimento quando menos bandas estão presentes nas últimas três faixas do gel. É possível verificar que certos microrganismos estão presentes em todas as faixas e algumas diferenças são visíveis principalmente na comunidade microbiológica da EFC em relação ao DC2.

A Figura 4 mostra como o material microbiológico do anodo e o líquido das EFC, DC1 e DC2 comportam-se no final do experimento. As réplicas mostradas na Figura 4 foram consistentes. Uma banda evidente é mostrada em todas as amostras dos experimentos da CEM que se refere àquela encontrada na Figura 3.

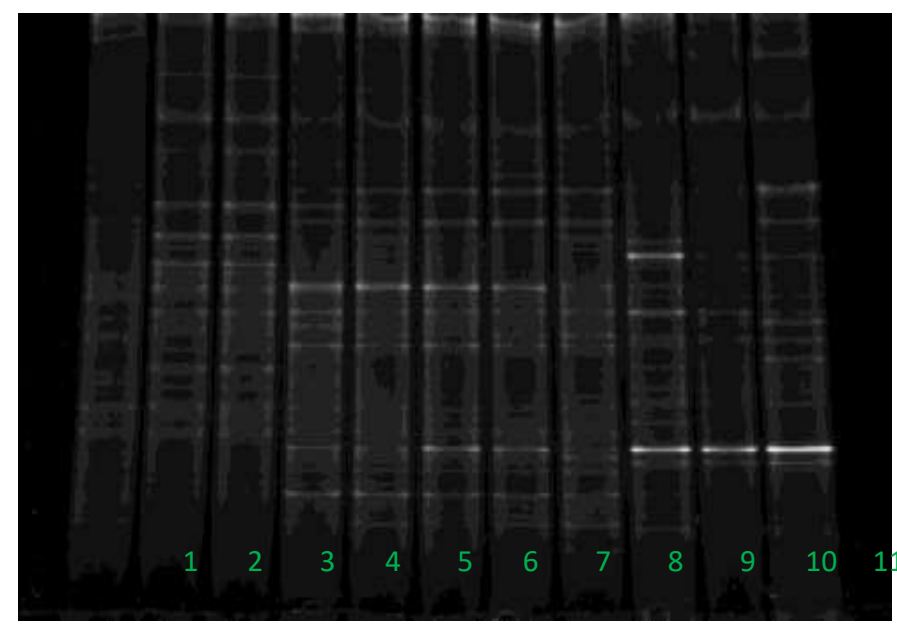

Figura 3: Gel DGGE com amostras no início (faixa 1 - efluente, faixas 2 e 3 rélica da amostra após o início), após 1o ciclo (faixa 4 - EFC, faixa 5-DC1, faixa 6 - DC2, faixa 7 - DC3, faixa 8 - DC4) e ao final do experimento (faixa 9 - EFC, faixa $10-D C 1$, faixa $11-D C 2$ ).

Amostras da EFC (Figura 4) foram relativamente diferentes das demais amostras o que indica que a comunidade microbiológica exerce uma certa influência na geração de energia. Além disso, amostras da superfície do material anódico e o líquido não mostraram diferenças relevantes.

As amostras de discos de carbono, no entanto, apresentaram algumas diferenças que poder sem facilmente identificadas na Figura 4. Logo, a porcentagem da composição dos discos exerce uma influência na medida que a comunidade microbiológica se associa ao material anódico e, consequentemente, à geração de energia. 


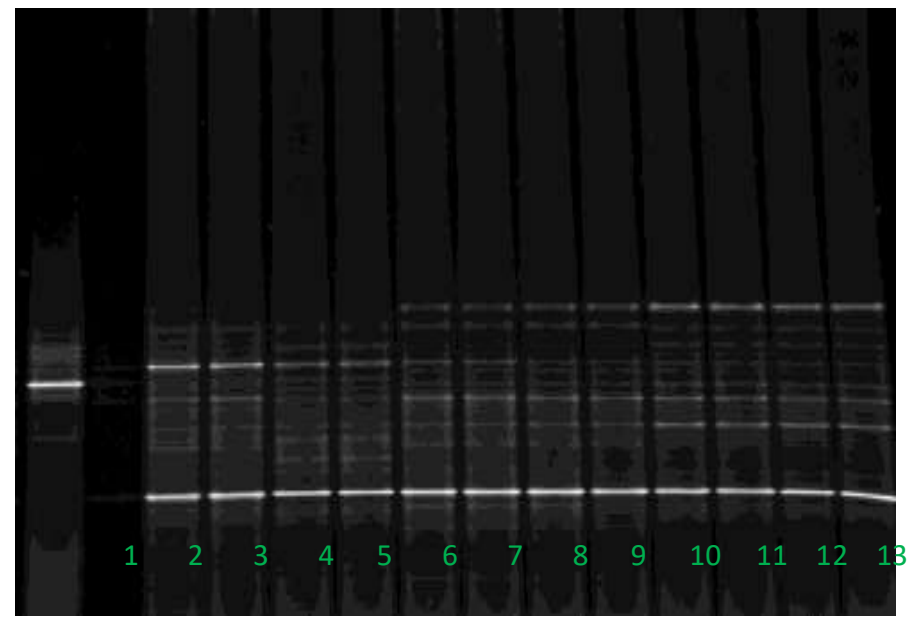

Figura 4: Gel DGGE da EFC, DC1 e DC2 do material anódico e líquido em replicata - Faixas 1 - controle positivo (E. coli); 2 - controle negativo; 3 - material anódico da EFC; 4 - réplica do material anódico da EFC; 5 - líquido da câmara EFC; 6 - réplica do líquido da câmara EFC; 7 - material anódico do DC1; 8 - réplica do material anódico do DC1; 9 - líquido da câmara DC1; 10 - réplica do líquido da câmara DC1; 11 - material anódico do DC2; 12 - réplica do material anódico DC2; 13 - líquido da câmara DC2; 14 - réplica do líquido da câmara do DC2.

Um total de 15 bandas foram selecionadas (de acordo com a intensidade) do gel DGGE de cada material anódico e líquido para o sequenciamento (Tabela 2). As diversidades microbiológicas foram diferentes para todos os materiais anódicos. No DC2, a predominância foi de Chlorobium e bactéria desconhecida (também encontrada no DC2 devido ao material), Serratia, Synechocysas, Synechocchus, já o EFC era constituído de Bacillus, Flavobacterium, Synechocchus e Porphyromonas.

É possível dizer que a quantidade de microrganismos encontrados nas bandas DGGE foram positivas para as amostras enviadas para o sequenciamento. É evidente que ambas as técnicas (clonagem e DGGE) são diferentes e geram resultados distintos. Na realidade, quando comparadas amostras das duas técnicas, o único grupo em comum é Chlorobium. Isto indica que este tipo de grupo é abundante especificamente para estes tipos de discos de carbono.

A diversidade microbiológica encontrada para as diferentes amostras de DGGE confirma o que tem sido descrito (Logan \& Regan, 2006) que uma quantidade limitada de substrato leva a uma competição entre as espécies presentes no meio. Esta seleção natural se inicia nas espécies presentes que irão variar até o ponto em que apenas as espécies dominantes permaneçam no meio. Isto pode ser visto com as espécies de Chlorobium que estão presentes na etapa final do processo. Os resultados não mostram a incidência de Chlorobium no início do processo. Isto, é claro, não significa que eles não estão presentes desde o início, mas apenas em que a sensibilidade do método DGGE sugere que as espécies de Chlorobium não eram predominantes nos estágios iniciais.

\subsection{A combinação dos métodos de identificação da comunidade microbiológica}

Como estudado por (Logan \& Regan, 2006), não há apenas uma espécie microbiológica presente no biofilme. Na realidade, há uma variedade de espécies que trabalham em conjunto para promover a biogeração de energia. Dessa maneira, a Figura 5 mostra que a combinação dos resultados da clonagem e DGGE em termos de anodo, líquido e líquido puro assemelham-se em 
termos da comunidade microbiológica. A Figura 5 resume a diversidade de microrganismos presentes no mesmo ambiente e como pequenas mudanças no material anódico podem diversificar as espécies presentes nos mesmos. Também evidencia como ambas técnicas em conjunto (clonagem Shotgun e DGGE) podem fornecer uma ideia mais ampla da comunidade microbiológica através da câmara da CEM em toda sua extensão e com o passar do tempo.

Tabela 2: 16sRNA microbiológico das bandas de DGGE de diferentes materiais anódicos empacotados nas CEMs.

\begin{tabular}{c|c|c|c}
\hline \multirow{2}{*}{ Tipo de Anodo } & \multicolumn{3}{|c}{ DGGE } \\
\cline { 2 - 4 } & Amostras submetidas & Amostras positivas & OTUs \\
\hline EFC & 5 & 4 & 4 \\
DC1 & 6 & 6 & 5 \\
DC2 & 4 & 4 & 3 \\
\hline
\end{tabular}

Portanto, a Table 2 revela que a abundância de microrganismos localizados no material anódico adere-se à superfície produzindo o biofilme. Embora se mostrem mais diversos na EFC, isso também acontece nos discos de carbono 1 e 2. É interessante notar que, quanto mais rápido os discos de carbono dissolvam-se no meio, maior será a quantidade de microrganismos encontrados neste meio líquido. Isto pode ser visto para o DC2. Assim sendo, a variedade da comunidade microbiológica é importante na eficiência da CEM, mas é também importante a maneira em que essa comunidade está disposta na câmara.

É possível que uma estrutura mais duradoura permita que a comunidade microbiológica atue mais eficiente na geração de energia. Entretanto, a principal pergunta a ser respondida é se de fato essa biodiversidade é responsável pela geração de energia ou ainda se há uma sucessão de microrganismos que precisam estar presentes para promover a geração de eletricidade.

Os autores ( $\mathrm{Ki}$ et al., 2008) sugerem que as espécies Bacteroidetes e Chlorobium provenientes do lodo ativado desenvolvem-se desenvolvem principalmente nos estágios finais e podem estar associadas com a geração de energia. Se compararmos os resultados obtidos na geração de energia (Figura 1) e os tipos microbiológicos encontrados (Figura 5), é possível perceber que a combinação dos dois tipos: Bacteroidetes e Chlorobium foi a que mostrou mais geração de energia. Também foi a que mostrou maior variedade microbiológica do biofilme. DC2 mostrou uma diversidade maior do que DC1 no meio líquido. Menos espécies aderidas ao anodo poderia explicar o porquê de a geração de energia ter sido a menor para este tipo de CEM.

Embora o mesmo substrato tenha sido usado em todas as câmaras, o material e a conformação dada pela análise de comunidade microbiológica mostraram que o tipo de anodo influencia na formação do filme, principalmente com o tempo. Dessa maneira, a diversidade microbiológica pode fornecer as necessidades de outro tipo de bactéria num estágio inicial e formar uma relação simbiótica durante todo o processo. 


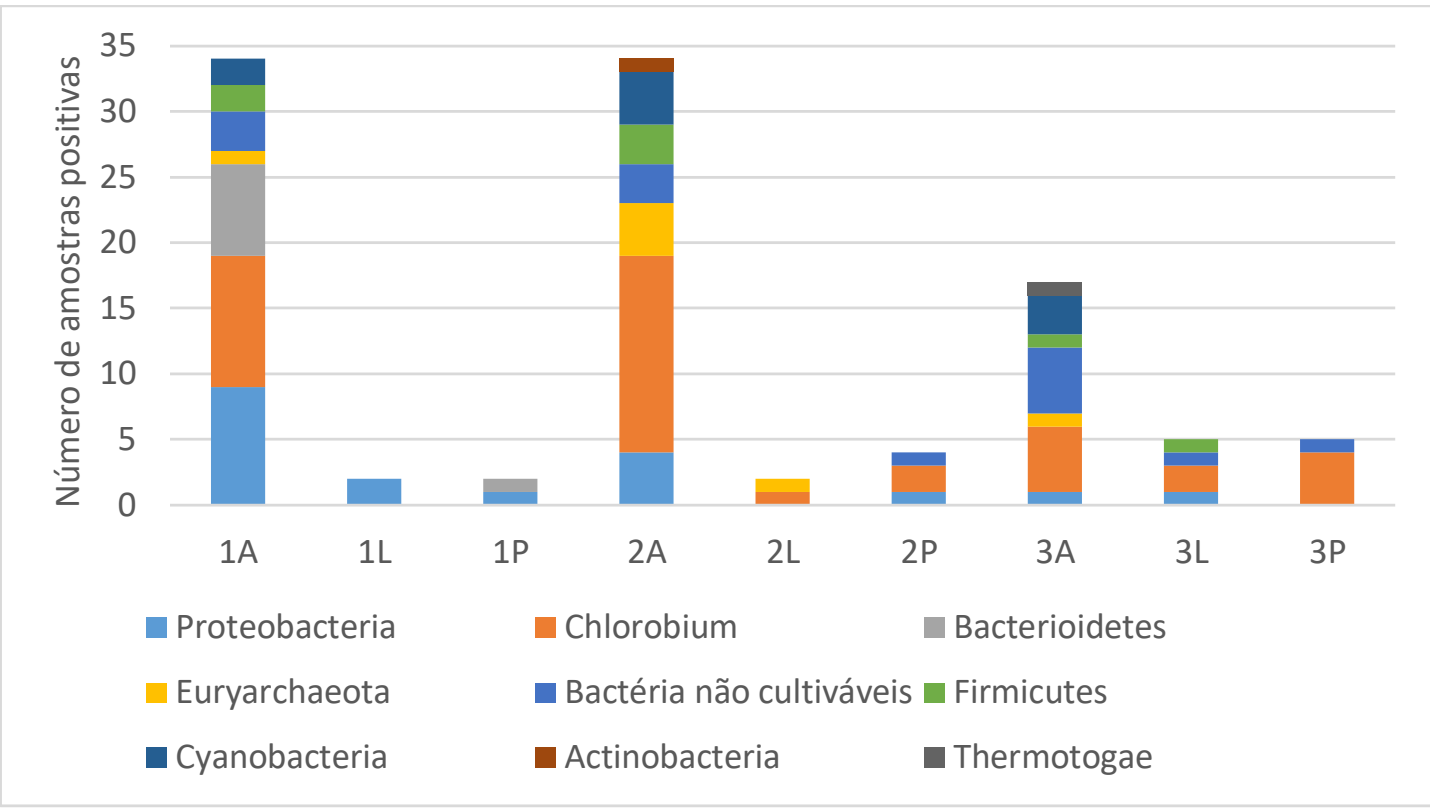

Figura 5: Análise da comunidade microbiológica para os três materiais anódicos da CEM (resultados da clonagem Shotgun + DGGE) - 1A (EFC - material anódico); 1L (EFC - líquido); 1P (EFC - líquido puro após filtragem); $2 A$ (DC1 material anódico); 2L (DC1 - líquido); 2P (DC1 - líquidp puro após filtragem); 3A (DC2 - material anódico); 3L (DC2 - líquido) e 3P ( DC2 - líquido puro após filtragem).

Tendo isso tem mente, os dois grupos de bactérias que foram encontrados predominantemente em todas as câmaras foram identificados pelo q-PCR como mostra a Figura 6. Como pode ser visto na Figura 6, em termos de porcentagem (razão do gene específico pelo total $16 \mathrm{~S}$ rRNA), Chlorobium aparenta ser o grupo de bactéria predominante nas CEMs.

A tendência mostrada pela Figura 6 comprova o descrito anteriormente de que este tipo de bactéria não está presente de forma significativa nos estágios iniciais da amostra de efluente utilizado neste CEM, mas tende a crescer conforme as condições duradouras tornem-se cada vez mais anaeróbias. A composição anódica pode influenciar na condição de crescimento deste tipo de bactéria.

Porém a incidência mais expressiva de Chlorobium no líquido e no líquido após a filtragem dos DC1 e 2, sugere que esta conformação degrada com o tempo. Como o biofilme dissolve-se no material anódico quando este também passa a desintegrar-se com o tempo, o Chlorobium é encontrado em maior quantidade no meio líquido do que no próprio material anódico. Por outro lado, um material anódico mais resistente, como a escova, providencia condições mais propícias ao crescimento de espécies como a Geobacter. Pode-se verificar que a Geobacter está presente em todos os estágios, em menor quantidade no efluente e mais expressiva no material que envolve a escova e, principalmente no material anódico, inclusive do DC1.

Além de se verificar a conformação do material anódico, escova ou disco, deve-se também prestar atenção na composição do material anódico. O EFC consiste em uma escova de fibra de carbono enquanto o DC1 consiste em um material que é $60 \%$ carbono e $40 \%$ argila. Uma vez que ambos os CEMs contêm proporções diferentes de carbono em suas composições, mas mesmo assim possuem geração de energia semelhante, então os resultados mostram que deve haver pelo menos uma combinação de $25 \%$ de Geobacter e Chlorobium no material anódico para que a CEM 
seja capaz de gerar uma quantidade relativa de energia independente da diversidade microbiológica.

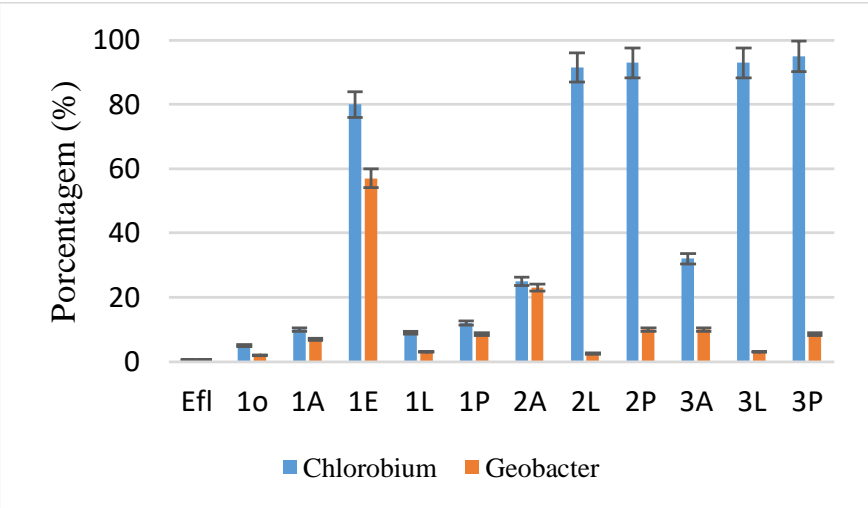

Figura 6: Proporção de Chlorobium e Geobacter em termos da diversidade microbiológica total para todas as câmaras através dos resultados de q-PCR - Efl (efluente); 10 (após o 10 ciclo); 1A (EFC - material anódico); 1E (EFC escova); 1L (EFC - líquido); 1P (EFC - líquido puro após filtragem); 2A (DC1 - material anódico); 2L (DC1 - líquido); 2P (DC1 - líquidp puro após filtragem); 3A (DC2 - material anódico); 3L (DC2 - líquido) e 3P ( DC2 - líquido puro após filtragem).

A conformação do material anódico na escova fornece naturalmente uma maior concentração microbiológica, mas talvez a deposição de múltiplas camadas de microrganismos não seja o suficiente para garantir o melhor desempenho de todos esses microrganismos. A CEM contendo DC1, por outro lado, fornece a quantidade suficiente para maximizar o biofilme formado por esta bactéria. Já na CEM contendo DC2, a proporção 50\% carbono e 50\% argila interfere no desenvolvimento de condições propícias para o crescimento de Geobacter. Embora tenha sido ideal para Chlorobium, e este seja capaz de gerar energia, a geração não é tão expressiva quanto se a Geobacter estivesse presente. Além disso, os resultados mostram que a maior geração de energia está associada realmente à relação simbiótica dos dois tipos de bactérias.

O desenvolvimento de novas metodologias pode aumentar a eficiência das CEMs tais como a mudança das características físicas como a espessura do biofilme. Para este estudo, o DC1 teve o melhor desempenho, pois a sua conformação e material anódico foi suficiente para produzir energia durante o tempo deste estudo. Sabe-se que esse tipo de disco se deteriora com o tempo e, para isso, conformações mais resistentes como a escova podem se tornar mais viáveis para células combustíveis de longa duração.

Os resultados mostrados neste estudo indicam que isso é possível. O principal obstáculo está na maneira de maximizar-se a eficiência. Como é comum para bactérias formar conglomerados na superfície, uma alternativa para aumentar a eficiência e produtividade e, portanto, uma maior bioremediação seria o de minimizar os efeitos dessa conglomeração e o crescimento excessivo do biofilme. Uma camada única de bactéria numa superfície de eletrodo pode produzir uma densidade de potencial máxima da ordem de $10^{3} \mathrm{~mW} / \mathrm{m}^{2}$ (Liu et al., 2004) para uma EFC. 


\section{CONCLUSÕES}

As densidades de potência máximas para EFC, DC1, DC2 mostraram uma tendência decrescente de $24 \mathrm{~mW} / \mathrm{m}^{3}, 20 \mathrm{~mW} / \mathrm{m}^{3}, 8 \mathrm{~mW} / \mathrm{m}^{3}$, respectivamente. Os discos de carbono 3 e 4 que continham grafite não foram estáveis durante todo o processo. Os discos de carbono começaram a desintegrar-se ao longo do tempo o que não permitiu a análise de densidade de potência. Portanto, o grafite não é um material adequado para ser usado em associação como disco de carbono.

Os resultados mostraram que os microrganismos na EFC da CEM variaram mais e a comunidade microbiológica consistiu em Geobacter, Myxococcus, Ignivibacterium, Chlorobium, Krokinobacter, Alistipes, Rhodopseudomonas, Pseudoxanthomonas, Xanthomonas, Citrumelo. 0 biofilme do material anódico do DC1 foi predominantemente de Rhodopseudomonas, Alistipes, Chlorobium, Geobacter, Aminobacterium. O DC2 consistiu em Chlorobium, Rhodopseudomonas, Erysipelothrix, Caldisericum, Oscillobacter. Conhecer a comunidade microbiológica da CEM é importante porque fornece um melhor indicador de como o crescimento microbiológico se desenvolve sob diferentes tipos de substratos, comum em amostras de efluentes. Usar novos materiais anódicos pode levar ao aumento da eficiência das CEMs, que é um método de geração de energia muito mais ambiental.

Diferentes tipos de substrato podem também ser usados em CEMs e suas aplicações podem ir além de estações de tratamento de efluentes domésticos. Aliás, estudos sugerem que a biorremediação e a geração de energia podem ser combinadas para outros tipos de efluentes industriais que são recalcitrantes demais para serem tratados por métodos biológicos convencionais. Dentre eles, o efluente têxtil e da indústria de papel. Alguns podem ser realizados em termos do substrato usado ou a combinação de um substrato complexo com açúcares simples que permitem a conversão eficiente da matéria orgânica em energia.

As CEMs também podem ser usadas em sedimentos marinhos. Algumas modificações como a adição de novas câmaras podem ser usadas no processo de dessalinização. Um estudo futuro pode analisar as CEMs apenas utilizando a Geobacter isolada. Esta monocultura pode providenciar evidências da CEM em relação ao fato de que a Geobacter é a grande responsável pela geração de energia ou se uma relação simbiótica com outros tipos de bactérias deve ser estabelecida para que isto aconteça.

O grande desafio, sem dúvida, está no desenvolvimento de CEMs que possam competir com outras formas de combustível. Acredita-se que as CEMs de hoje podem ser usadas como pequenos geradores portáteis de energia semelhantes a baterias o que mostra o longo caminho que deve ser explorado para que elas possam ser usadas em escalas maiores e tornem-se ainda mais economicamente viáveis na indústria ambiental atual. Os novos desenvolvimentos tecnológicos visam ampliar a aplicabilidade das CEMs. Sabe-se que elas são tecnologias capazes de gerar eletricidade ao mesmo tempo em que promovem a biorremediação.

O questionamento deve ser realizado no que se refere ao processo em si. E para que se possa ampliar o uso das CEMs, deve-se focar também no estudo a nível molecular. Citocromos, conformação da membrana celular e vias metabólicas podem ser ajustadas de forma a garantir 
melhor desempenho microbiológico. Enzimas podem ser adicionadas para reduzir a energia de ativação de modo que a degradação orgânica seja mais simples. Enzimas como a acilase podem interferir na comunicação bacteriana e reduzir a deposição de camadas de microrganismos no biofilme.

Para garantir que as CEMs possam competir com tecnologias de combustíveis fósseis, o custo dos reatores e a fonte de material devem ser considerados. As aplicações das CEMs estão apenas na fase inicial e muito pode ser feito para auxiliar a minimizar ou corrigir a geração excessiva de resíduos. A geração de energia de forma renovável é um desafio que deve ser levado a sério e as CEMs podem ser uma alternativa promissora neste aspecto.

\section{AGRADECIMENTOS}

Este estudo foi financiado pela University of Texas at San Antonio. Os autores agradecem a assistência técnica da Dra. Ruoting Pei neste projeto.

\section{REFERÊNCIAS}

Baron, D., LaBelle, E., Coursolle, D., Gralnick, J. A., \& Bond, D. R. (2009). Electrochemical Measurement of Electron Transfer Kinetics by Shewanella oneidensis MR-1. Journal of Biological Chemistry, 284(42), 28865-28873. doi: 10.1074/jbc.M109.043455

Bond, D. R., \& Lovley, D. R. (2003). Electricity Production by Geobacter sulfurreducens Attached to Electrodes. Applied and Environmental Microbiology, 69(3), 1548-1555. doi: 10.1128/AEM.69.3.1548-1555.2003

Cho, Y. K., Donohue, T. J., Tejedor, I., Anderson, M. A., McMahon, K. D., \& Noguera, D. R. (2008). Development of a solar-powered microbial fuel cell. Journal of Applied Microbiology, 104(3), 640-650. doi: 10.1111/j.1365-2672.2007.03580.x

Dias, F., Mesquita Oliveira, F., de Oliveira Matias, L., \& Martins Fernandes, T. (2019). Enriquecimento nutricional de resíduos de algas do gênero Gracilaria sp., utilizando Saccharomyces cerevisiae através de cultivo semissólido. HOLOS, 7, 1-18. doi:https://doi.org/10.15628/holos.2019.3451

Das, S., \& Mangwani, N. (2010). Recent developments in microbial fuel cells: a review. JOURNAL OF SCIENTIFIC \& INDUSTRIAL RESEARCH, 69(10), 727-731.

Fricke, K., Harnisch, F., \& Schroder, U. (2008). On the use of cyclic voltammetry for the study of anodic electron transfer in microbial fuel cells. ENERGY \& ENVIRONMENTAL SCIENCE, 1(1), 144-147. doi: 10.1039/b802363h

Greenman, J., Gálvez, A., Giusti, L., \& leropoulos, I. (2009). Electricity from landfill leachate using microbial fuel cells: Comparison with a biological aerated filter. Enzyme and Microbial Technology, 44(2), 112-119. doi: 10.1016/j.enzmictec.2008.09.012

$\mathrm{Hu}$, Z. (2008). Electricity generation by a baffle-chamber membraneless microbial fuel cell. Journal of Power Sources, 179(1), 27-33. doi: 10.1016/j.jpowsour.2007.12.094 
Huang, L., \& Logan, B. E. (2008). Electricity generation and treatment of paper recycling wastewater using a microbial fuel cell. Applied Microbiology and Biotechnology, 80(2), 349355. doi: 10.1007/s00253-008-1546-7

Jia, Y.-H., Tran, H.-T., Kim, D.-H., Oh, S.-J., Park, D.-H., Zhang, R.-H., \& Ahn, D.-H. (2008). Simultaneous organics removal and bio-electrochemical denitrification in microbial fuel cells. Bioprocess and biosystems engineering, 31(4), 315-321. doi: 10.1007/s00449-0070164-6

Katuri, K. P., \& Scott, K. (2010). Electricity generation from the treatment of wastewater with a hybrid up-flow microbial fuel cell. Biotechnology and bioengineering, 107(1), 52-58.

Ki, D., Park, J., Lee, J., \& Yoo, K. (2008). Microbial diversity and population dynamics of activated sludge microbial communities participating in electricity generation in microbial fuel cells. WATER SCIENCE AND TECHNOLOGY, 58(11), 2195-2201. doi: 10.2166/wst.2008.577

Kim, H. J., Hyun, M. S., Chang, I. S., \& Kim, B. H. (1999). A microbial fuel cell type lactate biosensor using a metal-reducing bacterium, Shewanella putrefaciens. JOURNAL OF MICROBIOLOGY AND BIOTECHNOLOGY, 9(3), 365-367.

Lee, T. K., Van Doan, T., Yoo, K., Choi, S., Kim, C., \& Park, J. (2010). Discovery of commonly existing anode biofilm microbes in two different wastewater treatment MFCs using FLX Titanium pyrosequencing. Applied Microbiology and Biotechnology, 87(6), 2335-2343. doi: 10.1007/s00253-010-2680-6

Li, X., \& Jia, R. (2008). Decolorization and biosorption for Congo red by system rice hullSchizophyllum sp. F17 under solid-state condition in a continuous flow packed-bed bioreactor. BIORESOURCE TECHNOLOGY, 99(15), 6885-6892. doi: 10.1016/j.biortech.2008.01.049

Liu, H., Ramnarayanan, R., \& Logan, B. E. (2004). Production of electricity during wastewater treatment using a single chamber microbial fuel cell. ENVIRONMENTAL SCIENCE \& TECHNOLOGY, 38(7), 2281-2285. doi: 10.1021/es034923g

Lloyd, J. R., Lovley, D. R., \& Macaskie, L. E. (2003). Biotechnological Application of Metalreducing Microorganisms (Vol. 53, pp. 85-128). United States: Elsevier Science \& Technology.

Logan, B. E. (2008). Microbial Fuel Cells (Vol. 1st). Hoboken: Wiley.

Logan, B. E., \& Regan, J. M. (2006). Electricity-producing bacterial communities in microbial fuel cells. TRENDS in Microbiology, 14(12), 512-518.

Lovley, D. R. (2006). Microbial fuel cells: novel microbial physiologies and engineering approaches. Current opinion in biotechnology, 17(3), 327-332.

Lovley, D. R. (2009). Future shock from the microbe electric. Microbial biotechnology, 2(2), 139141. doi: 10.1111/j.1751-7915.2009.00090_9.x 
Marsili, E., Baron, D. B., Shikhare, I. D., Coursolle, D., Gralnick, J. A., \& Bond, D. R. (2008). Shewanella Secretes Flavins That Mediate Extracellular Electron Transfer. Proceedings of the National Academy of Sciences of the United States of America, 105(10), 3968-3973. doi: 10.1073/pnas.0710525105

Murali, V., Ong, S. A., Ho, L. N., Wong, Y. S., \& Hamidin, N. (2013). Comprehensive Review and Compilation of Treatment for Azo Dyes Using Microbial Fuel Cells. WATER ENVIRONMENT RESEARCH, 85(3), 270-277. doi: 10.2175/106143012X13503213812481

Pant, D., Van Bogaert, G., Diels, L., \& Vanbroekhoven, K. (2010). A review of the substrates used in microbial fuel cells (MFCs) for sustainable energy production. BIORESOURCE TECHNOLOGY, 101(6), 1533-1543. doi: 10.1016/j.biortech.2009.10.017

Potter, M. C. (1911). Electrical Effects Accompanying the Decomposition of Organic Compounds. Proceedings of the Royal Society of London. Series B, Containing Papers of a Biological Character, 84(571), 260-276.

Qian, F., \& Morse, D. E. (2011). Miniaturizing microbial fuel cells. Trends in Biotechnology, 29(2), 62-69. doi: 10.1016/j.tibtech.2010.10.003

Rabaey, K., Boon, N., Siciliano, S. D., Verhaege, M., \& Verstraete, W. (2004). Biofuel Cells Select for Microbial Consortia That Self-Mediate Electron Transfer. Applied and Environmental Microbiology, 70(9), 5373-5382. doi: 10.1128/AEM.70.9.5373-5382.2004

Rezaei, F., Richard, T. L., \& Logan, B. E. (2008). Enzymatic hydrolysis of cellulose coupled with electricity generation in a microbial fuel cell. Biotechnology and bioengineering, 101(6), 1163-1169.

Richter, H., Nevin, K. P., Jia, H. F., Lowy, D. A., Lovley, D. R., \& Tender, L. M. (2009). Cyclic voltammetry of biofilms of wild type and mutant Geobacter sulfurreducens on fuel cell anodes indicates possible roles of OmcB, OmcZ, type IV pili, and protons in extracellular electron transfer. ENERGY \& ENVIRONMENTAL SCIENCE, 2(5), 506-516. doi: 10.1039/b816647a

Sharma, V., \& Kundu, P. P. (2010). Biocatalysts in microbial fuel cells. Enzyme and Microbial Technology, 47(5), 179-188. doi: 10.1016/j.enzmictec.2010.07.001

Shizas, I., \& Bagley, D. M. (2004). Experimental determination of energy content of unknown organics in municipal wastewater streams. JOURNAL OF ENERGY ENGINEERING-ASCE, 130(2), 45-53. doi: 10.1061/(ASCE)0733-9453(2004)130:2(45)

Sun, M., Sheng, G.-P., Mu, Z.-X., Liu, X.-W., Chen, Y.-Z., Wang, H.-L., \& Yu, H.-Q. (2009). Manipulating the hydrogen production from acetate in a microbial electrolysis cellmicrobial fuel cell-coupled system. Journal of Power Sources, 191(2), 338-343. doi: 10.1016/j.jpowsour.2009.01.087

Sun, Y. M., Wei, J. C., Liang, P., \& Huang, X. (2011). Electricity generation and microbial community changes in microbial fuel cells packed with different anodic materials. BIORESOURCE TECHNOLOGY, 102(23), 10886-10891. doi: 10.1016/j.biortech.2011.09.038 
Torres, C. (2012). Improving microbial fuel cells. Membrane Technology, 2012(8), 8-9.

Zuo, Y., Maness, P. C., \& Logan, B. E. (2006). Electricity production from steam-exploded corn stover biomass. ENERGY \& FUELS, 20(4), 1716-1721. doi: 10.1021/ef060033। 